\title{
Evaluation of Ashwagandha (Withania Somnifera) and its Extract to Protecting he Liver From Damage
}

\author{
Ebtihal Y. Khojah ${ }^{1}$ and Dalia A. Hafez ${ }^{1,2 *}$ \\ ${ }^{1}$ Food Science and Nutrition Department, Faculty of Science, Taif University, Kingdom of Saudi Arabia \\ ${ }^{2}$ Home Economic Department, Faculty of Education, Suez Canal University, Ismailia, Egypt.
}

\begin{abstract}
This study was achieved to the safety evaluation of the ashwagandha (Withania somnifera) and total phenolic acid and total flavonoids compounds were determined, as well as ABTS and DPPH radical scavenging activities assay were studied. In addition, the biological experimental was an examination of hepatitis rats.
\end{abstract}

The results observed that the ashwagandha root extract was safety due to no evidence of toxic effect or mortality in mice. This safety from the ashwagandha root extract caused the extract had contained high amounts of phenolic and flavonoids compounds which directly role of in free radical scavenging, thus the extract from ashwagandha root is a source of antioxidant activity.

At the end of biological experimental after eight weeks the results found that the effects of ashwagandha roots extract on carbon tetrachloride CCl4-induced changes in serum hepatic enzymes were decreased compared with control CCl4 positive and gives nearly equal control negative at level $400 \mathrm{mg} / \mathrm{kg}$ body weight for a rat. Moreover, the results found that the effect ashwagandha roots extract on antioxidant enzymes hepatic as glutathione (GSH), superoxide dismutase (SOD), malondialdehyde (MDA), glutathione peroxidase (GPx), and catalase (CAT) parameters showed that the ashwagandha roots extract was an improvement the antioxidant enzymes.

Furthermore, different concentrations extract alleviated histopathological changes in rats' liver treated with CCl4. Ashwagandha root extracts confirmed that the protection of the rats' liver CCl4- induced hepatotoxicity. This influence may be due to activated, the antioxidant activities of these extracts.

It could be recommended that the obviously results supported that the possible antihepatic damage effect of ashwagandha root extract against CCl4-induced hepatic damage. Therefore, the treatment with ashwagandha root on hepatic damage influence may be due to their natural antioxidants.

Keywords: Ashwagandha, Hepatic, Liver Enzyme, Toxicity

\section{INTRODUCTION}

Ashwagandha (Withania somnifera, family Solanaceae) is a significant great significance herb of Ayurveda system of medicine in India. It is utilized widely as possessing different health useful (1). Ashwagandha is Know recognized to its biologically active chemical compositions like the alkaloids, steroidal lactones, and saponins (2).The roots of ashwagandha are recognized for their pharmacological influence due to the presence of a group of steroidal lactones. Theutilize of ashwagandha has been apparent in the therapy of leukoderma, asthma, bronchitis, Parkinson's disease, and chronic liver disease, etc. $(\mathbf{3}, \mathbf{4})$.

Ashwagandha had contained various natural antioxidants that preservation the antioxidant liver enzymes which are responsible as a health promoter. It has been utilized to therapy inflammation, fevers and to protect against illness. It has been utilized to protect the immune system, become better memory and to promote overall wellness (6).

The roots of Withania somnifera had contained for the most of compounds known as withanolides, which are steroidal compounds and bear a resemblance to the active constituents known as ginsenosides. Ashwagandha's withanolides have been the influence on many statuses; including the immune system and even cancer (7). Chemical analysis of Ashwagandha was observed that the major components to be alkaloids and steroidal lactones. Moreover, the Ashwagandha leaves had contained steroidal lactones, which are commonly called withanolides $\mathbf{( 8 )}$.

Aim of this study was achieved to estimate the ashwagandha root powder for natural antioxidant content and activity and also and its extract as protect of the liver from damage.

\section{MATERIALS AND METHODS}

\section{Materials}

Ashwagandha (Withania somnifera) roots were obtained from local market and it was properly washed under running water to remove adhering foreign particles, mud, dust, etc., dried at low temperature $\left(50^{\circ}-60^{\circ} \mathrm{C}\right)$ and ground under hygienic 
conditions to powder form using traditional stone pestle and mortar as well as an electric grinder. The powder so obtained was sieved twice to remove the coarse particles and stored in airtight containers until further analysis.

\section{Acute oral toxicity for animals}

\section{METHODS}

Healthy young male albino mice were used for acute oral toxicity study. Eighteen mice (weighing 20-30 g) were purchased from Pharmacy College at King Saud University. The rats were randomly divided into 3 groups of 6 mice per cage to measure the LD50 of the Ashwagandha root. The ambient temperature in the experimental laboratory was maintained at $22{ }^{\circ} \mathrm{C}( \pm 3$ $\left.{ }^{\circ} \mathrm{C}\right)$. A standard pellet diet was given with water ad libitum. For experiment designed to determine oral LD50 of ashwagandha (Withania somnifera) sighting study was done on one rat which was administered $2000 \mathrm{mg} / \mathrm{kg}$ ashwagandha roots powder. Signs of toxicity were observed for 14 days. No toxic effects were seen in the sighting study; hence $2000 \mathrm{mg} / \mathrm{kg} \mathrm{dose} \mathrm{was} \mathrm{selected} \mathrm{for} \mathrm{the}$ main study in five rats. Rats were administered the dose of $2000 \mathrm{mg} / \mathrm{kg}$ of ashwagandha (Withania somnifera) and signs and symptoms of toxicity were observed (9). On day 15, all the animals were euthanized and gross pathological examinations were done.

\section{Subacute toxicity}

Healthy male albino mice (24 mice weighing 20-30 g) were purchased from Pharmacy Collage at King Saud University and delivered to the King Fahd Medical Research Center in Jeddah) were divided into 4 groups of 6 mice per cage randomly. Rats were given oral (gavages) ashwagandha of root in the doses of 0 (Group I control), 500 (Group II low-dose), 1000 (Group III mid dose), 2000 (Group IV high-dose) mg/kg/day for 28 days. During the course of sub-acute study, all animals were provided an ad libitum feed, until the day prior to the scheduled euthanasia(10).After 28, animals from Groups I to IV were euthanized, blood was collected from a retro-orbital vein for estimated Red blood cells (RBCs) and white blood cells (WBCs) were measured as recommended by Riley (11). Blood hemoglobin ( $\mathrm{Hb}$ ) and platelets were determined using a whole blood sample and the method described by Dacie and Lewis (12) and PCV was determined according to the equation:

\section{$\mathrm{PCV}=\underline{\text { The volume of erythrocytes in a given volume of blood }}$}

Total blood volume

\section{Estimation of total phenolic acids and total flavonoids compounds}

The total phenolic content in the extract was measured using the method of Qawasmeh et al. (13) with Folin-Ciocalteu reagent. The UV reading was measured at $760 \mathrm{~nm}$. Gallic acid was used as standard $(1 \mathrm{mg} / \mathrm{ml})$ and the results were expressed as gallic acid equivalents (GAE $\mathrm{mg} / 100 \mathrm{~g}$ of dry weight).

The total flavonoids content was determined by the method of Eghdami and Sadeghi (14). The absorbance was measured against a blank solution at $510 \mathrm{~nm}$ and the total flavonoid content was expressed in terms of milligrams of quercetin equivalent per gram dry weight (mg QE /100g DW).

\section{Determination methods of antioxidant activity in ashwagandha root powder ABTS (2, 2-Azinobis (3-ethylbenzothiazoline-6-sulfonic acid) diammonium salt)}

The ABTS assay was performed according to the method used by Miller and Rice-Evans (15) and Ramesh Kumar and Sivasudha (16). For the analysis, $1 \mathrm{~mL}$ ABTS reaction solution was added to $100 \mu \mathrm{L}$ sample extract, and the absorbance was measured at $734 \mathrm{~nm}$ immediately after $1 \mathrm{~min}$ of initial mixing.

\section{DPPH (1,1-Diphenyl-2-picrylhydrazyl)}

The DPPH assay was performed as described by Ravichandran et al. (17) the absorbance of the mixture was measured at515 nm with the UV-Visible spectrophotometer. The following formula was used to determine the percentage of scavenging activity,

Percentage of inhibition $(\%)=\left[\left(\mathrm{A}_{\text {control }}-\mathrm{A}_{\text {sample }}\right) / \mathrm{A}_{\text {control }}\right] \times 100$

Where, $\mathrm{A}_{\text {control- }}$ absorbance of DPPH,

$\mathrm{A}_{\text {sample-absorbance reaction of mixture (DPPH with Sample) }}$

\section{Biological experimental}

Male albino rats ( $\mathrm{n}=36$ rats), 150-200g per each, were purchased from Pharmacy Collage at King Saud University and delivered to the King Fahd Medical Research Center in Jeddah. Rats were housed in individual cages and fed on a basal diet appropriate according to described with Pell et al. (18). 
All rats were fed on the basal diet for one-week before starting the experiment for acclimatization. After feeding on a basal diet for eight days, rats were divided into six groups. The first group considered normal control fed on basal diet and receiving paraffin oil 3ml/kg-1 body weight, subcutaneous (Sc) two times per week and normal saline $5 \mathrm{ml} / \mathrm{kg}-1$ body weight, per orally (Po) four times per week for eight weeks. The second groups considerable $\mathrm{CCl} 4$ as positive control fed on basal diet and receiving carbon tetrachloride $40 \%$ in paraffin oil $(3 \mathrm{ml} / \mathrm{kg}-1$ body weight, Sc) two times per week for eight weeks and normal saline $(5 \mathrm{ml} /$ kg-1 body weight, Po) four times per week for eight weeks. The third, fourth, fifth and sixth groups were fed on basal diet and receiving carbon tetrachloride $40 \%$ in paraffin oil ( $3 \mathrm{ml} / \mathrm{kg}-1$ body weight, Sc) two times per week for eight weeks and 100 , 200, 300 and $400 \mathrm{mg} /$ per orally $/ \mathrm{kg}-1$ body weight two times per week for eight weeks from Ashwagandha root extract separately as well as normal saline $5 \mathrm{ml} / \mathrm{kg}-1$ Po body weight, four times per week for eight weeks. Each rat was weighed every two days and the food consumption was calculated.

At the end of the experiment, twenty-four hours after dosing of vehicle, CCl4 or plant extracts, blood samples were collected from the orbital sinus. Serum was separated by centrifugation at $3500 \mathrm{rpm}$ and kept under $-7^{\circ} \mathrm{C}$ for the determination of liver enzymes. Animals were anesthetized with diethyl ether and sacrificed for separation of the liver. Livers were dissected out, divided into two parts. One part was kept in liquid nitrogen for determination of antioxidant status and the other part was immediately fixed in formaldehyde solution $10 \%$ and was used for histopathological examination.

Serum Aspartate aminotransferease (AST) and alanine aminotransferease (ALT) were determined colorimetrically following Schumann and Klauke (19), while Serum alkaline phosphatase (ALP) detected according to Belifield and Goldberg (20).

The activity of the antioxidant enzymes, Catalase (CAT) was measured according to the method of Aebi (21). Superoxide dismutase (SOD) was measured by Janknegt et al. (22). Glutathione Peroxidase (GPX) was measured by Paglia and Valentine (23). Reduced glutathione (GSH) level was measured according to the chemical method described by Moron $\boldsymbol{e t}$ al.(24), while lipid peroxidation products were determined by measuring malondialdehyde (MDA) content in tissue homogenates, according to the method of Uchiyama and Mihara (25).

\section{Histopathological examination}

Liver tissues were preserved in $10 \%$ formaldehyde solution was used for histopathological study. The kidney tissues were placed in plastic cassettes and immersed in neutral buffered formalin for $24 \mathrm{~h}$. The fixed tissues were processed routinely, embedded in paraffin, cut into 4-5 $\mu$ m-thick sections and stained with hematoxylin and eosin (H\&E).

\section{Statistical analysis:}

All chemical analyses were performed in three replicates and the results were statistically analyzed. Statistical analysis was performed using the GLM procedure with SAS (26) software.

\section{RESULTS AND DISCUSSION}

\section{Acute and Sub-acute toxicity for ashwagandha (Withania somnifera) roots}

In acute toxicity study, oral LD50 of ashwagandha (Withania somnifera) roots extract in mice was taken orally at level $2000 \mathrm{mg} / \mathrm{kg}$ body weight. During fourteen days it could not be observed in the acute oral toxicity in rats and no abnormal behavior during the experimental period. Moreover, it could be noticed that the ashwagandha (Withania somnifera) roots extract did not produce any organ atrophy and hypertrophy.

Sub-acute toxicity was evaluated if the extract from ashwagandha roots has any effect on blood parameters and packed cell volume (PCV) and the findings are tabulated in Table (1). The outcomes observed no statistical variations (P>0.05) when PCV were compared among the groups at the post-treatment groups (after 28 day). Moreover, the PCV was slightly decreased in the treated group at levels 500,1000 and $2000 \mathrm{mg} / \mathrm{kg} / \mathrm{day}$ weight were $50.51,50.29$ and $50.16 \%$, respectively, than control group was $50.78 \%$ after 28 days. These results confirm that the ashwagandha root extract was taken up to $2000 / \mathrm{mg} / \mathrm{kg} / \mathrm{day}$ to rats for $28 \mathrm{days}$ has no negative influence on the parameters were found..These results confirmed by Dewick (27) and Jones and Kinghorn (28) observed that the ashwagandha (Withania somnifera) roots extract relatively safe for mice when given orally. A slight lowering in PCV showed in behave toward groups in sub-acute toxicity exam could be a reason may be these plant had contained saponins in the extract which is known to due to hemolysis by growing the permeability of the plasma membrane.

From the results, it could be noticed that the increase in WBC, RBC, Hemoglobin and Platelets, the ratios of all the experimental groups were in the normal range. Haemoglobin observed that increase in normal when the animals' are therapy with ashwagandha (Withania somnifera) roots extract (29). Ashwagandha (Withania Somnifera) root extract reported that no proof of toxic influence in mice (30). 
Table (1): Sub-acute toxicity tests of the Ashwagandha (Withania somnifera) roots extract in mice.

\begin{tabular}{|l|l|l|l|l|}
\hline Blood samples & Group 1 as control & Group II low dose & Group III mid dose & Group IV high dose \\
\hline RBC $10^{6} / \mathrm{cm}$ & $8.41 \pm 0.39$ & $8.75 \pm 0.35$ & $8.99 \pm 1.07$ & $9.95 \pm 1.12$ \\
\hline WBC $10^{3} / \mathrm{cm}$ & $9.15 \pm 0.33$ & $10.82 \pm 1.02$ & $11.52 \pm 1.08$ & $12.24 \pm 1.14^{*}$ \\
\hline PCV $\%$ & $50.78 \pm 2.58$ & $50.51 \pm 1.74$ & $50.29 \pm 1.21$ & $50.16 \pm 1.76$ \\
\hline Platelets $10^{3} / \mathrm{cm}$ & $922.1 \pm 30.27$ & $941 \pm 42.54$ & $968.5 \pm 30.28$ & $988.6 \pm 33.37$ \\
\hline Hemoglobing/dl & $11.34 \pm 0.4$ & $12.99 \pm 1.05$ & $13.19 \pm 1.13$ & $15.00 \pm 1.21$ \\
\hline
\end{tabular}

Values are mean and SD $(n=3)$; where: Mean values in the same with the letter are significantly different at 0.05 levels

\section{Antioxidant content and activity from ashwagandha roots extract}

Antioxidant content as phenolic content and flavonoids compounds and antioxidant activity as DPPH and ABTS radical scavenging ability were determined in ash wagandha (Withania somnifera) roots extract and the findings are illustrated in Table (2). The outcomes found the total phenolic content and flavonoids compounds were $45.32 \mathrm{mg}$ gallic acid/100 $\mathrm{g}$ and $32.27 \mathrm{mg}$ quercetin equivalent $(\mathrm{QE}) / 100 \mathrm{~g}$, respectively. These results confirmed with Harikrishnan et al. (31) reported that the extract from Ashwagandha roots had contained several alkaloids, a few flavonoids and reducingsugars besides rich in iron. Moreover, Udayakumar et al. (32) reported that the total phenolic acids and flavonoids compounds were lower may be caused by the various sources of $W$. somnifera and polyphenols compounds of the different plant parts which may be concerning to the color, maturity, and environment. The scavenging capacity of DPPH free radicals is utilized to screen the antioxidant potential of foods and plants. The antioxidant capacity of the extract of Withania somnifera roots had contained a good antioxidant capacity as shown in Table (2). A significant lowering was found in the DPPH radical activity may be caused by the scavenging capacity of the extracts.

The ABTS radical scavenging capacity was reported to be increased in Withania somnifera root extract. ABTS • radical is usually utilized for the examination of antioxidants in the beverages and plant extracts for their antioxidant activities for the reason that of its power in both the organic and aqueous media $(\mathbf{3 3}, \mathbf{3 4})$.

Table (2): Antioxidant content and activity from ashwagandha roots extract

\begin{tabular}{|c|c|}
\hline Antioxidant content and activity & Ashwagandha extract \\
\hline Total phenolic (TP) mg/100g GAE & $45.32 \pm 7.45^{\mathrm{a}}$ \\
\hline Total flavonoids (TF) mg/100g QE & $32.27 \pm 2.05^{\mathrm{a}}$ \\
\hline DPPH (inhibitions percent) & $65 \pm 8.29^{\mathrm{c}}$ \\
\hline ABTS (inhibitions percent) & $85 \pm 10.19^{\mathrm{b}}$ \\
\hline
\end{tabular}

Values are mean and $\mathrm{SD}(\mathrm{n}=3)$; where: Mean values in the same with the letter are significantly different at 0.05 levels

\section{BIOLOGICAL EXPERIMENTAL:}

\section{Effect of ashwagandha (Withania somnifera) roots extract on initial, final body weight and feed efficiency ratio in rats:}

The findings present in Table (3) pointed out the effect of ashwagandha (Withania somnifera) roots extract on the body weight and nutrition value in rats. The outcomes observed that the normal control group had the highest in final body weight by $40.8 \mathrm{~g}$, increased in gain bodyweight $40.2 \mathrm{~g}$ and feed efficiency ratio by5.89\% after eight weeks. Meanwhile, the positive group was treated with carbon tetrachloride and fed on basal diet slightly significantly increased in initial body weightby $3.3 \mathrm{~g}$ and feed efficiency ratio was $0.85 \%$. Meanwhile, the rat groups fed on ashwagandha (Withania somnifera) roots extract orally two times per week at levels $100,200,300$ and $400 \mathrm{mg} / \mathrm{kg}$ body weight rat was observed that no significant changes in final body weight increasing by 7.6, 10.3, 15.2 and $20.4 \mathrm{~g}$, respectively. Meanwhile the total the feed efficiency ratio showed that the different concentrations from ashwagandha extract were increased gradually by $1.58,1.95,2.64$ and $3.27 \%$, respectively. It means that the ashwagandha (Withania somnifera) roots extract had contained rich amounts from the natural antioxidant. These results confirmed with Udayakumar et al., (35) who found the extract of W. somnifera is a large number of phytochemicals and also, the pharmacological effect of the roots of $W$. somnifera is attributed to natural antioxidants including phenolic compounds and flavonoids 
Table (3):Influence of ashwagandhaextract on body weight and feed efficiency ratio in rats

\begin{tabular}{|c|l|l|l|l|l|}
\hline Groups & Initial body weight g & $\begin{array}{c}\text { Final body } \\
\text { weight } \mathrm{g}\end{array}$ & $\begin{array}{c}\text { Gain body weight } \\
\mathrm{g}\end{array}$ & $\begin{array}{c}\text { Total food } \\
\text { intake }\end{array}$ & $\begin{array}{c}\text { Feed efficiency } \\
\text { ratio }\end{array}$ \\
\hline Control negative & $200.6 \pm 7.26$ & $240.8 \pm 8.39$ & $40.2 \pm 0.91$ & $672 \pm 5.21$ & $5.98 \pm 0.15$ \\
\hline Control CCl 4 & $210.7 \pm 9.13$ & $213.4 \pm 6.81$ & $3.3 \pm 0.63$ & $390 \pm 2.18$ & $0.85 \pm 0.01$ \\
\hline $100 \mathrm{mg}$ & $207.7 \pm 6.89$ & $214.1 \pm 8.28$ & $7.6 \pm 0.27$ & $480 \pm 3.29$ & $1.58 \pm 0.04$ \\
\hline $200 \mathrm{mg}$ & $200.5 \pm 9.86$ & $210.2 \pm 9.28$ & $10.3 \pm 0.65$ & $528 \pm 3.19$ & $1.95 \pm 0.03$ \\
\hline $300 \mathrm{mg}$ & 205.78 .57 & $220.2 \pm 9.37$ & $15.2 \pm 0.43$ & $576 \pm 4.37$ & $2.64 \pm 0.07$ \\
\hline $400 \mathrm{mg}$ & $190.6 \pm 8.62$ & $210.2 \pm 5.64$ & $20.4 \pm 0.26$ & $624 \pm 5.11$ & $3.27 \pm 0.09$ \\
\hline
\end{tabular}

Data are presented as mean $(\mathrm{n}=6$ rats $) \pm$ standard deviation

\section{Effect of ashwagandha root extract on liver functions}

Table (4) showed influence of ashwagandha roots on liver function indices of rats when feeding with the ashwagandha roots at various levels $100,200,300$ and $400 \mathrm{mg} / \mathrm{kg}$ body weight rat.The results from alanine transaminase (ALT), aspartate transaminase (AST) Alkaline phosphatase (ALK) showed that the highest increased in the control positive was 55.0, 15.0 and $65.0 \mathrm{mg} / \mathrm{dl}$ than control negative was $20.0,8.0$ and $35.0 \mathrm{mg} / \mathrm{dl}$, respectively. The treatment of different groups found that the improvement of liver functions gradually when the concentration ashwagandha root was increasing. The activity of ALT, AST and ALP was significantly reduced in rats group fed orally at concentrate $400 \mathrm{mg}$ ashwagandha roots to $22.9,8.2 \mathrm{and} 39.0 \mathrm{mg} / \mathrm{dl}$, respectively.

These results confirmed that with Elberry $\boldsymbol{e t}$ al. (36)who evaluated that the antihepatotoxic and antioxidant characteristics observed a significant antihepatotoxic influence.In another research, ashwagandha roots were analyzed for antihepatotoxic activity CC14-induced in male rats. The results found that the aqueous extract $400 \mathrm{mg} / \mathrm{kg}$ body weight had significant antihepatotoxic activity and lowering the elevated levels of serum enzymes and increasing total protein (37).

Table (4). The effects of ashwagandha roots extract on carbon tetrachloride $\mathrm{CCl}_{4}$-treated induced alterations in serum hepatic enzymes

\begin{tabular}{|c|c|c|c|}
\hline Groups & ALT $(\mathrm{mg} / \mathrm{dl})$ & AST $(\mathrm{mg} / \mathrm{dl})$ & ALP(mg/dl) \\
\hline Control negative & $20.0 \pm 1.0^{\mathrm{d}}$ & $8.0 \pm 1.00^{\mathrm{d}}$ & $35.0 \pm 3.28^{\mathrm{e}}$ \\
\hline Control CCl 4 & $55.0 \pm 2.65 \mathrm{a}$ & $15.0 \pm 0.97^{\mathrm{a}}$ & $53.0 \pm 4.16^{\mathrm{a}}$ \\
\hline $100 \mathrm{mg}$ & $49.0 \pm 0.91^{\mathrm{a}}$ & $13.0 \pm 0.99^{\mathrm{a}}$ & $40.0 \pm 5.07^{\mathrm{b}}$ \\
\hline $200 \mathrm{mg}$ & $35.5 \pm 0.90^{\mathrm{b}}$ & $10.3 \pm 1.13^{\mathrm{b}}$ & $30.0 \pm 4.91^{\mathrm{d}}$ \\
\hline $300 \mathrm{mg}$ & $30.4 \pm 1.00^{\mathrm{c}}$ & $9.7 \pm 1.00^{\mathrm{c}}$ & $39.0 \pm 3.27^{\mathrm{e}}$ \\
\hline $400 \mathrm{mg}$ & $22.9 \pm 1.00^{\mathrm{d}}$ & $8.2 \pm 1.71^{\mathrm{d}}$ & \\
\hline
\end{tabular}

Values are mean and $\operatorname{SD}(n=6)$; where: Mean values in the same with the letter are significantly different at 0.05 levels.

\section{Effect of ashwagandha roots extract on the activity of the antioxidant enzymes liver parameters:}

Results presented in Table (5) showed that the effect of ashwagandha roots extract on the activity of the antioxidant enzymes liver parameters. From the results, it could be noticed that GSH, GPx, MDA, and SOD parameter were the highest in control positive by $96.88 \mathrm{~m} \mathrm{~mol} / 1,79.11 \mathrm{~m} \mathrm{~mol} / 1,12.20 \mathrm{mmol} / 1$ and $553.27 \mu / \mathrm{g}$, respectively exception of CAT was the lowest 0.50 $\mu \mathrm{m} / \mathrm{g}$. Whilst, control positive showed that lowering in all parameters exception CAT was the highest at $9.09 \mu \mathrm{m} / \mathrm{g}$. Moreover, the treatment different groups were gradually significant increased and improved the antioxidant at $400 \mathrm{mg} /$ bodyweight rat to 90.59 $\mathrm{mmol} / 1,77.16 \mathrm{~m} \mathrm{~mol} / 1,11.58 \mathrm{mmol} / \mathrm{l}$ and $545.36 \mu / \mathrm{g}$, respectively and CAT was the improved to $0.9 \mu \mathrm{m} / \mathrm{g}$ as a result near control negative. These results are occurred by Zarei and Shivanandappa (38) who suggested that the rats pre-treated with ashwagandh aroots the perturbation was significantly attenuated, which was indicated by reduction in lipid peroxidation level and enhancement of antioxidant states (SOD, GPx and CAT) when compared with those of normal rats.

The antioxidant enzyme livers are considered to be preventive antioxidant as they inhibition free radical chain by lowering the available concentration of free radical to initiate the process (39). 
Table (5): Effect ashwagandha roots extract on antioxidant enzyme liver

\begin{tabular}{|l|l|l|l|l|c|}
\hline Groups & \multicolumn{1}{|c|}{$\begin{array}{c}\text { GSH } \\
(\mathrm{m} \mathrm{mol} / \mathrm{l})\end{array}$} & $\begin{array}{c}\text { G- Px } \\
(\mathrm{m} \mathrm{mol} / \mathrm{l})\end{array}$ & $\begin{array}{c}\text { MDA } \\
(\mathrm{m} \mathrm{mol} / \mathrm{l})\end{array}$ & $\begin{array}{c}\text { CAT } \\
(\mathrm{u} / \mathrm{mg})\end{array}$ & $\begin{array}{c}\text { SOD } \\
\mu / g\end{array}$ \\
\hline Control negative & 96.88 & 79.11 & 12.20 & 0.50 & 553.24 \\
& $\pm 8.25^{\mathrm{a}}$ & $\pm 7.26^{\mathrm{a}}$ & $\pm 1.53^{\mathrm{a}}$ & $\pm 0.01^{\mathrm{e}}$ & $\pm 22.15^{\mathrm{a}}$ \\
\hline Control CCl 4 & 14.08 & 9.58 & 5.09 & 9.09 & 350.19 \\
& $\pm 2.04^{\mathrm{e}}$ & $\pm 1.22^{\mathrm{e}}$ & $\pm 0.43^{\mathrm{e}}$ & $\pm 1.32^{\mathrm{a}}$ & $\pm 16.21^{\mathrm{c}}$ \\
\hline $100 \mathrm{mg}$ & 22.19 & 20.04 & 8.69 & 4.68 & 410.24 \\
& $\pm 2.46^{\mathrm{d}}$ & $\pm 2.38^{\mathrm{d}}$ & $\pm 0.67^{\mathrm{d}}$ & $\pm 0.53^{\mathrm{b}}$ & $\pm 21.32^{\mathrm{b}}$ \\
\hline $200 \mathrm{mg}$ & 43.63 & 41.31 & 9.50 & 3.67 & 453.10 \\
& $\pm 3.59^{\mathrm{c}}$ & $\pm 3.86^{\mathrm{c}}$ & $\pm 0.76^{\mathrm{c}}$ & $\pm 0.11^{\mathrm{c}}$ & $\pm 15.25^{\mathrm{ab}}$ \\
\hline $300 \mathrm{mg}$ & 66.64 & 57.61 & 10.48 & 2.49 & 499.59 \\
& $\pm 3.12^{\mathrm{b}}$ & $\pm 2.27^{\mathrm{b}}$ & $\pm 1.08^{\mathrm{b}}$ & $0.21^{\mathrm{d}}$ & $\pm 11.28^{\mathrm{ab}}$ \\
\hline $400 \mathrm{mg}$ & 90.59 & 11.58 & 0.90 & 545.36 \\
& $\pm 5.28^{\mathrm{a}}$ & \pm 7.16 & $\pm 1.24^{\mathrm{a}}$ & $\pm 0.08^{\mathrm{e}}$ & $\pm 28.71^{\mathrm{a}}$ \\
\hline
\end{tabular}

Values are mean and SD $(n=6)$; where: Mean values in the same with the letter are significantly different at 0.05 levels.

\section{HISTOPATHOLOGICAL EXPERIMENTAL:}

\section{Effect of ashwagandha roots extract on histopathological disorders:}

Microscopically, liver of rats from the group (1) (control negative) showed the normal histological structure of hepatic lobule (photo 1). Meanwhile, liver of rats from the group (2) (control positive) revealed congestion of central vein, cytoplasmic vacuolation of hepatocytes (photo 2), congestion of hepatic sinusoids and few leucocytes in the hepatic sinusoids (photo 3 ). The previous results agreed withQuine and Raghu, (40) who suggested that abnormal developments have been considered direct evidence of improved hepatopathies, due to swelling, inflammation and necrotic processes. Moreover, Kang et al.(41)have shown that with the progression of hepatopathies, increases of liver weight due to the fibrosis or abnormal glycosylation related hepatosteatosis and hepatocyte hypertrophic changes, due to lipid depositions in the cytoplasm. However, the liver of rats from the group (3) showed no changes except the congestion of hepatic sinusoids (photo 4). Congestion of the central vein was the only change observed in the liver of rats from the group (4) (photo 5). Meanwhile, the liver of rats from the group (5) revealed congestion of hepatic sinusoids (photo6). Slight congestion of hepatic sinusoids (photo7) and slight cytoplasmic vacuolation of hepatocytes were noticed in the liver of rats from the group (6).

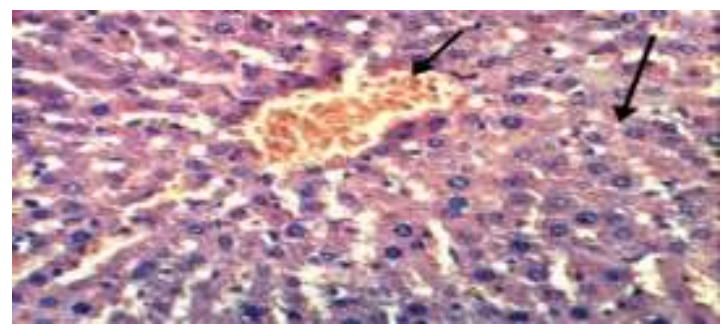

Photo (1): Liver rat group (1) showing the normal histological structure of hepatic lobule (H \& E X 400).

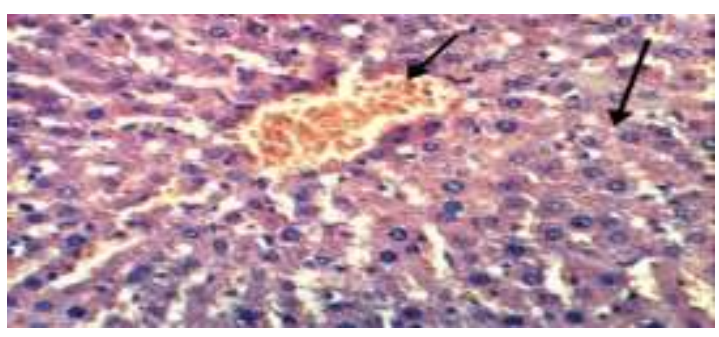

Photo (2): Liver rate group (2) showing congestion of central vein and cytoplasmic vacuolation of hepatocytes (H \& $\mathbf{E}$ 400). 


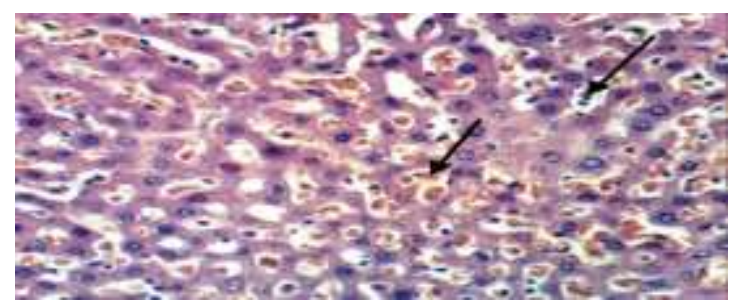

Photo (3): Liver rat group (2) showing congestion of hepatic sinusoids and few leucocytes in the hepatic sinusoids (H \& E X 400).

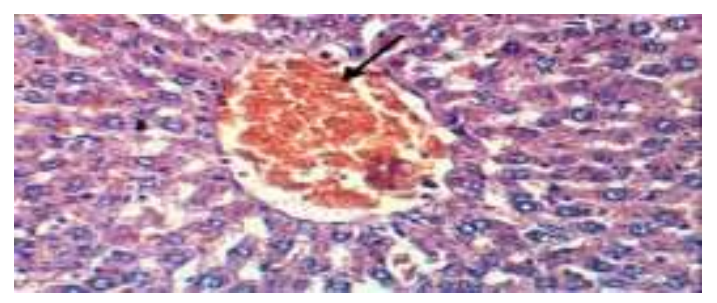

Photo (4): Liver rat f group (3) showing congestion of central vein (H \& E X 400).

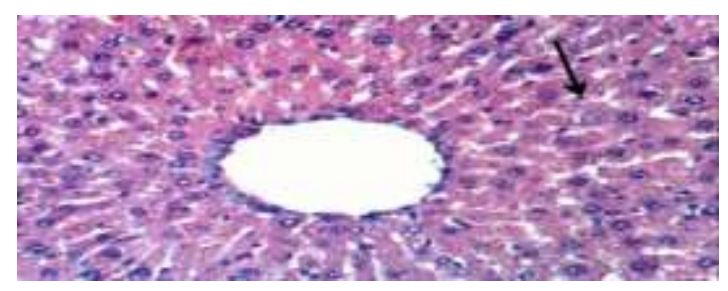

photo (5): Liver of rat from group (4) showing Kupffer cells activation (H \& E X 400).(

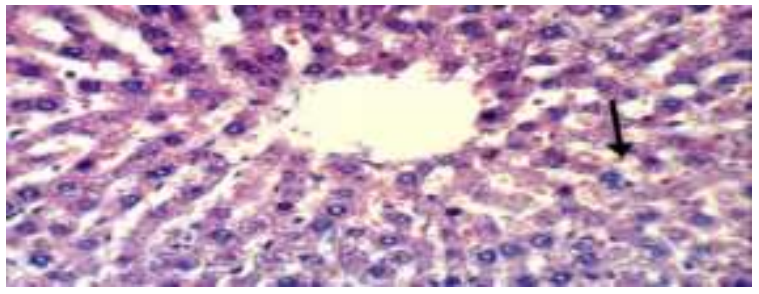

Photo (6): Liver of rat from group (5) showing slight cytoplasmic vacuolation of hepatocytes (H \& E X 400).

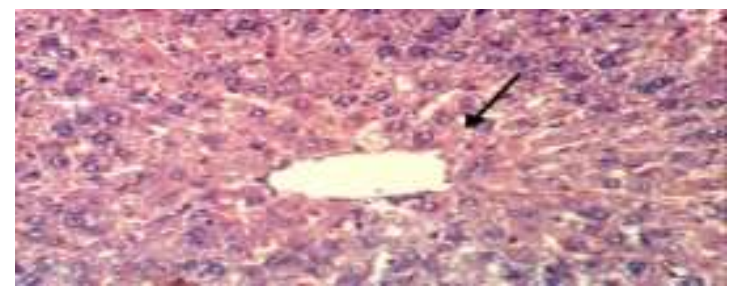

Photo (7): Liver of rat from group (6) showing slight granularity of the cytoplasm of hepatocytes (H \& E X 400). 


\section{CONCLUSION}

The results from this study found that the ashwagandha roots extract had contained rich amounts from the natural antioxidant activity which can preserve the liver against damages induced by free radicals which are produced as the result of $\mathrm{CCl} 4$ metabolism. The results also demonstrated that the ashwagandha roots extract which improved the antioxidant enzyme liver.

\section{REFERENCES}

[1] Singh N, Bhalla M, Jager P, Gilca M (2011). An overview on ashwagandha: A rasayana (rejuvenator) of ayurveda. Afr J Tradit Complement Altern Med 8:208-213.

[2] Mishra LC, Singh BB, Dagenais S (2000) Scientific basis for the therapeutic use of Withania somnifera (ashwagandha): A review. Altern Med Rev, 5:334-346.

[3] ChoudharyM, KumarV, MalhotraH, SinghS (2015)Medicinalplantswithpotentialanti-arthriticactivity.JIntercultEthnopharmacol,4:147-179.

[4] PalliyaguruDL,SinghSV,KenslerTW(2016)Withaniasomnifera:Frompreventiontotreatmentofcancer.MolNutrFoodRes,60:1342-1353.

[5] Mehta M. (2013). Development of low cost nutritive biscuits with Ayurvedic formulation. International Journal of Ayurvedic and Herbal Medicine. 2013;3(3):1183:1190.

[6] Singh, G., Sharma, P. K., Dudhe, R. and Singh S. (2010). Biological activities of Withania somnifera, Annals of Biological Research, 2010, 1 (3) : 56-63

[7] Grandhi, A. , Mujundar, A M. and Patwardhan, B (1994). A comparative pharmacological investigation of ashwagandha and ginsedg, Journal of Ethnopharmacology (Ireland), 1994: vol. 3,131-135

[8] Jayaprakasam, B., Zhang, Y., Seeram, N.P and Nair, M.G. (2003), Growth Inhibition of Human Tumor Cell Lines by Withanolides from Withania somnifera Leaves, Life Sciences,74,125-132.

[9] Kumar D, Bhat ZA, Shah MY. (2012). Effect of successive extracts of Stachys tibetica Vatke (Lamiaceae) in anxiety. Orient Pharm Exp Med, 12: 247-253.

[10] Patel, S B.,. Rao, N J. and Hingorani, L L. (2016). Safety assessment of Withania somnifera extract standardized for Withaferin A: Acute and subacute toxicity study, Journal of Ayurveda and Integrative Medicine 7 (2016)30e37

[11] Riley, V.(1960).Adaptationoforbital bleedingtechniqueto rapidserialblood studies.Proc. Soc. Exp.Biol.Med.,109 :751-754.

[12] Dacie, J. V. and Lewis, S. M. (1984). Practical hematology. Churchill Living Stone. London and NewYork.

[13] Qawasmeh, A., Obied, H. K., Raman, A., \& Wheatley, W. (2012). Influence of fungal endophyte infection on phenolic content and antioxidant activity in grasses: Interaction between Lolium perenne and different strains of Neotyphodium lolii. Journal of Agricultural and Food Chemistry, 60(13),3381-3388.

[14] Eghdami, A., \& Sadeghi, F. (2010). Determination of total phenolic and flavonoids contents in methanolic and aqueous extract of Achillea millefolium. Journal of Organic Chemistry, 2,81-84.

[15] Miller, N.J.; Rice-Evans, C.A. (1997). Factors influencing the antioxidant activity determined by the ABTS.+ radical cation assay. Free Radic. Res. 1997, 26, 195-199. [CrossRef][PubMed]

[16] Ramesh Kumar A., and Sivasudha T. (2012). In vitro antioxidant and antibacterial activity of aqueous and methanolic extract of Mollugo nudicaulis Lam Leaves, Asian Pac J Trop Biomed. 2(2), 895-900(2012).

[17] Ravichandran, K.; Ahmed, A.R.; Knorr, D.; Smetanska, I. (2012). The effect of different processing methods on phenolic acid content and antioxidant activity of red beet. Food Res. Int. 2012, 48, 16-20.[CrossRef]

[18] Pell, J.D., Gee, J.M., Wortley, G.M. and Johnson, I.T. (1992). Both dietary corn oil and guar gum stimulate intestinal crypt cell proliferation in rats, by independent but potentially synergistic mechanisms. J. Nutr., 122,2447-2456.

[19] Schumann G, Klauke R. New IFCC reference procedures for the determination of catalytic activity concentrations of five enzymes in serum: preliminary upper reference limits obtained in hospitalized subjects. Clin. Chem. Acta, 2003, 327:69-79.

[20] BelfieldAandGoldbergDM.Revisedassayforserumphenylphosphataseactivityusing4-amino-antipyrine.Enzymemol.,1971,12(5):561-586.

[21] Aebi, M.E. (1995): Catalase. In: Bergmeyer J, Grabl BM (eds) Methods of Enzymatic Analysis vol. III. Enzymes oxidoreductases, 3rd ed. Weinheim: Verlag-Chemie. Pp:273-286.

[22] Janknegt, P.J.; Rijstenbil, J.W.; van de Poll, W.H.; Gechev, T.S. and Buma, A.G. (2007): A comparison of quantitative and qualitative superoxide dismutase assays for application to low temperature microalgae. J. Photoch em. Photobiol. B Biol., 87,218-226.

[23] Paglia, D. E. and W. E. Valentine (1967): Studies on the quantitative and qualitative characterization of erythrocyte glutathione peroxidase. J. Lab. Clin. Med. 1,158-169.

[24] Moron MS, Diperre JW, Mannervik B. Levels of glutathione, glutathione reductase and glutathione-S-transferase activities in rat lungs and liver. Biochim Biophys Acta 1979;582:67-71.

[25] UchiyamaM,MiharaM. Determinationofmalonaldehydeprecursorintissuesbythiobarbituricacid test. AnalBiochem1978;86:271-8.

[26] Wang Y, Han T, Xue LM, Han P, Zhang QY, Huang BK. Hepatotoxicity of kaurene glycosides from Xanthium strumarium L.fruits in mice. Pharmazie, 2011; 66: 445-449

[27] SAS (2004). Statistical Analysis System. SAS User's Statistics SAS Institute Inc. Editors, Cary,NC.

[28] Dewick PM. (2002). Medicinal Natural Products: A Biosynthetic Approach (2nd edn). JohnWiley and Sons Ltd: Cichester;220.

[29] Jones P and Kinghorn D. 2006. Extraction of plant secondary metabolites. In: Methods in Biothechnology Natural Products Isolation (2nd edn). Sarker D, Latif Z, Gray A (eds). Humana Press: Totowa;269-273.

[30] Aphale AA, Chhibba AD, Kumbhakarna NR, Mateenuddin M, Dahat SH. (1998). Subacute toxicity study of the combination of ginseng (Panax ginseng) and Ashwagandha (Withania somnifera) in rats: a safety assessment. Indian J Physiol Pharmacol1998;42:299-302

[31] Prabu PC, Panchapakesan S, Raj CD. (2013). Acute and sub-acute oral toxicity assessment of the hydroalcoholic extract of Withania somnifera roots in Wistar rats. Phytother Res2013;27:1169-78

[32] Harikrishnan, B., Subramanian, P. and Subash. S (2008). Effect of Withania somnifera root extract on the levels of circulatory lopod peroxidation and lover marker enzymes in chronic hyperammonemia. E.J. Chem.,5:872-877.

[33] Udayakumar R, Kasthurirengan S, Vasudevan A, Mariashibu TS, Rayan JJS, Choi CW, Ganapathi A, Kim SC (2010). Antioxidant Effect of Dietary SupplementWithaniasomniferaL.ReduceBloodGlucoseLevelsin Alloxan-InducedDiabeticRats.PlantFoodsHumNutr2010,65:91-98. 
[34] Huang M.H., Huang S.S., Wang B.S., Wu C.H., Sheu M.J., and Hou W.C. (2011). Antioxidant and anti-inflammatory properties of Cardiospermum halicacabum and its reference compound ex vivo and in vivo, J Ethnopharmacol. 133, 743-750(2011).

[35] Srikanth G., Manohar B.S., Kavitha C.H.N., Bhanoji Rao M.E., Vijaykumar N., and Pradeep C.H. (2010) Senthil R.K., Rajkapoor B. and Perumal P., Antioxidant activities of Indigofera cassioides Rottl. Ex. DC. Using various in vitro assay models, Asian Pac J Trop Biomed. 2(4), 256261(2012).

[36] DahiruD,JohnOO,UmaruHA.(2003).EffectofHibiscussabdariffacalyxextractinCCl4inducedliverdamage.Biokemistri.2003,15(1):27-33.

[37] Elberry AA, Harraz FM, Ghareib SA, Nagy AA, Gabr SA, Suliaman MI. Anti-hepatotoxic effect of Marrubium vulgare and Withania sommifera extracts on carbon tetrachloride-induced hepatotoxicity in rats. J Basic Clin Pharm 2010; 1(4):247-254.

[38] Mubashir HM, Bahar A, Suroor AK, Shah MY, Shamshir K. Antihepatotoxic activity of aqueous extract of Marrubium vulgare whole plant in CCl4 induced toxicity. Indian J Nat Prod., 2009; 25:3-8.

[39] Zarei M and Shivanandappa T. Amelioration of cyclophosphamide-induced hepatotoxicity by the root extract of Decalepis hamiltonii in mice. Food Chem. Toxicol. 2013,57:179-184.

[40] Winston GWandDi GiulioRT.Prooxidantandantioxidant mechanismsinaquaticorganisms.Aquat.Toxicol.1991,19,137-161.

[41] Chen JC, Tsai CC, Chen LD, Chen HH and Wang WC. (2000). Therapeutic effect of gypenoside on chronic liver injury and fibrosis induced by CCl4 in rats. Am. J. Chin. Med., 2000,28(2):175-185. 